\title{
Access for Performance of Transportation Planning and Operations: Case Study in Beijing Metropolitan Region
}

\author{
Y. G. Wang ${ }^{* 1}$, C. B. Zhang ${ }^{2}$, Y. Cao ${ }^{3}$, B. H. Liu ${ }^{4}$ \\ ${ }^{1,2}$ School of Highway, Chang'an University, Xi'an 710064, China \\ *sdqdwyg@163.com \\ 3 Traffic \& Transportation School, Dalian Jiaotong University, Dalian 116028, China \\ ${ }^{4}$ Transportation institute, Shijiazhuang Tiedao University, Shijiazhuang 050043, China
}

\begin{abstract}
Considering the importance of maintaining effective performance at desired levels, the Transportation Adaptability Performance Index, as a weighted multi-criteria combination approach, is proposed to continuously identifying the performance of degradable transportation networks and making effective supplement, contrapuntal revision and intime adjustment of the program implementation process, in response to new requirements of the urban system. For the design of strategic and quantitative methodology, 50 variables belonging to 8 domains in 2 components are chosen as the original input inherently reflecting the various interests of involved stakeholders. Specifically, the paired comparison matrix of the domain is constructed by the analytic hierarchy process to weight the importance of each single variable. If the consistency of the matrix is acceptable, the domain weight in two components is determined directly through the singular value decomposition approach and while the consistency level is unacceptable, the significant element in the matrix is identified and revised until the consistency satisfies the constraint. The methodology is then applied to evaluate the performance of transportation networks in Beijing metropolitan region using the derived 2000 2010 data and the findings indicate that the hidden and potential problems could be quantitatively identified by this approach that can be used as a user-friendly tool for metropolitan planning organizations in assessing the effectiveness and efficiency of in-service infrastructures, updating plans, setting priorities and optimizing resource allocation for next step.
\end{abstract}

Keywords: transportation planning, adaptability performance index, paired comparison matrix, acceptable consistency, singular value decomposition, significant element.

\section{Abbreviation Terms}

AADT Annual average daily traffic

API Air pollution index

ASD Average stopped delay

BRT Bus rapid transit

$\mathrm{Cl} \quad$ Consistency index

CR Consistency ratio

GDP Gross domestic product

HCM Highway capacity manual

ITS Intelligent transportation system

LOS Level of service

$\mathrm{km} \quad$ Kilometer

NAAQS National ambient air quality standards

RI Random index

SVD Singular value decomposition

TIA Traffic impact analysis

veh Vehicle

\section{Introduction}

To evaluate the effectiveness of transportation planning in urban regions, the interaction between all the activities in the urban regions and their relevant impact in the urban economy, the society and the ecological environment must be taken into consideration together since the primary purpose of transportation planning is to construct a viable and efficient support for urban economy development, maintain the equity and social inclusion and reduce the environmentally negative impacts [1]. Concerning this statement, it is very important to evaluate the transportation network performance in order to diagnose the existing problems in the implementation process and adequate it to a real sustainable urban development. 
Performance variables, also known as performance objectives, targets, measures, or measures of effectiveness (MOEs), are indicators that evaluate the progress toward "success" in achieving the original stated goals or aims. Though it is not specific to transportation, much has been reported regarding the use of performance variables to monitor and improve the effectiveness of the implementing transportation programs and more than 500 detailed variables have been developed [2, 3]. Such performance variables may track one specific goal: with a focus on congestion, a series of congestion related variables may be unarguably able to monitor the system's operation and efficiency [4]. However, the growing recognition of the inevitability of traffic congestion gauges progress towards a new philosophy of transportation planning strategies $[5,6]$, which include not only expansion of existing facilities, but better operation harmony in an overall system of environment, society and economy dependently.

Unlike the capacity-oriented concept, sustainable transportation planning is about a multimodal transportation network providing mobility and safety to its users, and considers transportation planning as a part of the urban system and is concerned with the goals of safety, livable communities, economic, energy, land use and air quality [4, 7]. Most recently, therefore, how to measure and assess the effectiveness of implementing transportation planning in supporting urban system has attracted various research interests $[8,9]$, especially in developing countries like China [10], so as to provide a direct understanding for the different involved stakeholders (planners, builders, managers and users) as well as to contribute a shift in reconsidering the draft programs and implementation plans [11]. Nowadays, long-range transportation planning (LRTP) is too little and LRTPs mostly have evolved from their initial long-range plans into short-term programs by enriching and updating the early agreements at different implementation stages in a project's budget, design, and schedule [12]. For example, an updated LRTP (Six Year Improvement Programs, SYIP), in Hampton Roads region of Virginia, is actually used rather than seeing consistent in 25-year period [2].

Unfortunately, however, similar issues have not been considered as a part of the overall transportation planning process for decades in Chinese cities. Despite having released its first LRTP in the beginning of 1980s, Beijing has drafted a new LRTP that lasted until 2004, and during these periods, few new demands were considered and supplemented to certain contents [13]. Therefore, as expected, it is necessary to develop a monitoring and evaluating procedure based on transportation variables related to urban system dimensions in China [14, 15]. Hence, this paper presents research contributing to optimize some performance variables that characterize transportation adaptability for China's specific condition in the metropolitan area and formulate an indicator based multi-criteria modeling process.

\section{Data}

Obviously, transportation planning is independent from environment, society and economy, and thus an effective and adaptable project should support the effective development of the urban system [16, 17], which features five objectives accordingly: 1) human-oriented facilities and livable streets; 2) friendly accessibility, health and safety; 3 ) equity and social inclusion; 4) support of a viable and efficient economy; 5) protection of the natural and ecological environment.

For simplification, the performance variables here are categorized into two components (Component $A$ and $B$ ) belonging to 8 domains, namely: a) social development, b) economic growth, c) life quality, d) ecological environment, e) reliability, f) efficiency, g) safety, h) operation. The first four domains in Component $A$ are summarized as they highlight the systemic urban development progress while being more or less, directly or indirectly, influenced by the level of transportation network performance. The last four domains in Component $B$ are of most significance in extensively monitoring and reporting the transportation network performance in detail.

To illustrate the applicability of the multi-criteria variable approach in measuring the performance of transportation networks, this study has used the Beijing metropolitan region as a case study. During the recent two decades, the population of Beijing city and vehicle ownership have grown rapidly, which has brought increasing challenges to the transportation networks [13]. In response to the increasing traffic demand, the transportation 
authorities have invested to develop an effective transit-oriented urban transport system to tickle the traffic congestion problems $[13,14,17]$. Here, 50 single variables are originally developed, as shown in Tables 1 and 2, respectively, for estimating the performance of regional transportation plans and operations, as a case example, and Table 3 summarizes the original 50 hierarchical variables over 2000-2010 statistics from governmental reports.

\begin{tabular}{|c|c|c|c|c|}
\hline Performance variable & Unit & Definition items & Type & Sym \\
\hline \multicolumn{4}{|l|}{ Social development } & $\mathrm{O}_{1}$ \\
\hline Urbanization level & $\%$ & $\begin{array}{l}\text { A national economic and social development } \\
\text { of integrated objectives, including population, } \\
\text { land resources, et al }\end{array}$ & I & $x_{1}$ \\
\hline Population density & $\mathrm{p} / \mathrm{km}^{2}$ & Population per unit area or unit volume & II & $x_{2}$ \\
\hline Gini coefficient & & Inequality of income or wealth distribution & II & $x_{3}$ \\
\hline Unemployment & $\%$ & Unemployment proportion & II & $x_{4}$ \\
\hline Health service level & Sheet & Hospital beds per 100,000 persons & $\mathrm{I}$ & $x_{5}$ \\
\hline $\begin{array}{l}\text { Education investment } \\
\text { rate }\end{array}$ & $\%$ & $\%$ financial expenditure in education & I & $x_{6}$ \\
\hline Driver education & $\%$ & $\%$ drivers in education and training & $\mathrm{I}$ & $x_{7}$ \\
\hline \multicolumn{4}{|l|}{ Economic growth } & $\mathrm{O}_{2}$ \\
\hline GDP per capita & $\begin{array}{l}10000 \\
\mathrm{CNY}\end{array}$ & GDP / registered citizen population & I & $\mathrm{X}_{8}$ \\
\hline Social service & $\%$ & Tertiary industry / GDP & $\mathrm{I}$ & $x_{9}$ \\
\hline Industrial efficiency index & $\%$ & $\begin{array}{l}\text { Measure of industrial enterprises' economic } \\
\text { efficiency }\end{array}$ & I & $x_{10}$ \\
\hline Retail sales per capita & CNY & Retail sales / registered citizen population & $\mathrm{I}$ & $x_{11}$ \\
\hline \multicolumn{4}{|l|}{ Life quality } & $\mathrm{O}_{3}$ \\
\hline Engel coefficient & $\%$ & $\%$ expense on food & II & $x_{12}$ \\
\hline Living comfort & $\mathrm{m}^{2}$ & Living space per capita & $\mathrm{I}$ & $x_{13}$ \\
\hline Motorization & pcu & Vehicle ownership per 10,000 people & $\mathrm{I}$ & $x_{14}$ \\
\hline Travel expenditure & $\%$ & $\%$ annual expenditures on travel & II & $x_{15}$ \\
\hline $\begin{array}{l}\text { Clean energy } \\
\text { consumption }\end{array}$ & $\%$ & $\begin{array}{l}\% \text { clean energy consumption for ultra-low } \\
\text { emission }\end{array}$ & I & $x_{16}$ \\
\hline \multicolumn{4}{|l|}{ Ecological environment } & $\mathrm{O}_{4}$ \\
\hline Environmental utilization & $\mathrm{m}^{2}$ & Green space per capita & $\mathrm{I}$ & $x_{17}$ \\
\hline Environment protection & $\%$ & $\%$ investment in environmental protection & $\mathrm{I}$ & $x_{18}$ \\
\hline Weather quality index & $\%$ & $\%$ days above level 2 in a year & $\mathrm{I}$ & $x_{19}$ \\
\hline $\mathrm{API}$ & & A composite index measuring air pollution & II & $x_{20}$ \\
\hline Noise pollution & $\mathrm{dB}$ & Average regional environmental noise & II & $x_{21}$ \\
\hline $\begin{array}{l}\% \text { intersections heavily } \\
\text { polluted }\end{array}$ & $\%$ & $\%$ intersections beyond NAAQS & II & $x_{22}$ \\
\hline $\begin{array}{l}\% \text { segments heavily } \\
\text { polluted }\end{array}$ & $\%$ & $\%$ road segments beyond NAAQS & II & $x_{23}$ \\
\hline Dust pollution & $\begin{array}{l}10000- \\
\text { ton }\end{array}$ & Dust emissions per year & II & $x_{24}$ \\
\hline Environment protection & $\%$ & $\begin{array}{l}\% \text { areas sensitive to emission and noise } \\
\text { under protection }\end{array}$ & $\mathrm{I}$ & $x_{25}$ \\
\hline Road greening & $\mathrm{km} / \mathrm{km}^{2}$ & $\mathrm{Km}$ road greening level per unit area & $\mathrm{I}$ & $x_{26}$ \\
\hline
\end{tabular}

Table 1. Explanatory performance variables of Component $A$. 


\begin{tabular}{|c|c|c|c|c|}
\hline Performance variable & Unit & Definition items & Type & Sym \\
\hline \multicolumn{4}{|l|}{ Reliability } & $\mathrm{O}_{5}$ \\
\hline Road distribution & $\begin{array}{l}\mathrm{km} / 100 \\
\mathrm{~km}^{2}\end{array}$ & Road network density & I & $x_{27}$ \\
\hline Road equality for residents & $m^{2}$ & Road areas per capita & $\mathrm{I}$ & $x_{28}$ \\
\hline Road equality for vehicles & $m^{2}$ & Road areas per veh & $\mathrm{I}$ & $x_{29}$ \\
\hline Freight volume & 10000-ton & Annual Freight Tonnage & $\mathrm{I}$ & $x_{30}$ \\
\hline Transit facilities & stb & Number of buses per 10,000 persons & $\mathrm{I}$ & $x_{31}$ \\
\hline Pedestrian accommodations & $\%$ & $\% \mathrm{~km}$ with sidewalk coverage & I & $x_{32}$ \\
\hline Bicycle users & $\%$ & $\% \mathrm{~km}$ with bike lane / shoulder coverage & $\mathrm{I}$ & $x_{33}$ \\
\hline \multicolumn{4}{|l|}{ Efficiency } & $\mathrm{O}_{6}$ \\
\hline$\%$ transit & $\%$ & Travel proportion in transit & $\mathrm{I}$ & $x_{34}$ \\
\hline $90 \%$ Trip time & $\%$ & $\begin{array}{l}\text { Maximum trip time accepted by } 90 \% \\
\text { travelers }\end{array}$ & I & $x_{35}$ \\
\hline Vehicles per lane km & & AADT $\times$ length / lane km & II & $x_{36}$ \\
\hline Transit service & $\min$ & Average bus wait time & I & $x_{37}$ \\
\hline Hub service & $\%$ & $\%$ individual perception of hub LOS & $\mathrm{I}$ & $x_{38}$ \\
\hline ITS & $\%$ & $\begin{array}{l}\% \mathrm{~km} \text { coordination with capable variable } \\
\text { message signs }\end{array}$ & I & $x_{39}$ \\
\hline \multicolumn{4}{|l|}{ Operation } & $\mathrm{O}_{7}$ \\
\hline \% segment heavily congested & $\%$ & $\% \mathrm{~km}$ at LOS E or F & II & $x_{40}$ \\
\hline $\begin{array}{l}\% \text { intersections heavily } \\
\text { congested }\end{array}$ & $\%$ & $\%$ intersections at LOS E or F & II & $x_{41}$ \\
\hline Delay savings & $\mathrm{s} / \mathrm{km}$ & Average travel delay per $\mathrm{km}$ & II & $x_{42}$ \\
\hline Transit support & $\%$ & $\%$ intersections with buses signal priority & $\mathrm{I}$ & $x_{43}$ \\
\hline Policy \& regulation & $\%$ & $\%$ programs that undertook TIA & $\mathrm{I}$ & $x_{44}$ \\
\hline Opportunities provision & 10000 & Jobs offered in planning process & $\mathrm{I}$ & $x_{45}$ \\
\hline \multicolumn{4}{|l|}{ Safety } & $\mathrm{O}_{8}$ \\
\hline Traffic accident risk & $\mathrm{mvk}$ & Accidents per million veh-km & II & $x_{46}$ \\
\hline Seriousness of accident & & Fatalities / injuries & II & $x_{47}$ \\
\hline Safety management & $\%$ & $\begin{array}{lll}\% & \text { arterial intersections } & \text { intelligently } \\
\text { controlled } & & \\
\end{array}$ & I & $x_{48}$ \\
\hline Safety equipments & sheet $/ \mathrm{km}$ & Signs per km per lane & $\mathrm{I}$ & $x_{49}$ \\
\hline Pedestrian safety & $\%$ & \% individual awareness above safety & I & $x_{50}$ \\
\hline
\end{tabular}

Table 2. Explanatory performance variables of Component B.

Among these variables, LOS is a general measure of traffic operating conditions within an intersection or roadway section. HCM 2000 defines six levels of service and each level has a definition indicated by a letter, from $A$ to $F$, with LOS A representing the best operating conditions and LOS F the worst. For intersections, LOS is determined by the ASD per vehicle and LOS E describes very congested driving conditions with delays averaging greater than 55 and up to 80 seconds per vehicle for signalized intersection and $35<A S D<50$ for unsignalized intersection, respectively. Signalized or unsignalized intersection that has LOS F means the ASD greater than 80 or 50 seconds per vehicles. For urban streets, the roadway under LOS $E$ has significant delays with average travel speeds of one-third or less of the free flow speed (greater than $35 \mathrm{mph}$ ). Moreover, traffic condition becomes much worse when the LOS reduces from $E$ to $F$ and the travel speed is extremely low, typically 33 or $25 \%$ of the free flow speed.

However, the original input variables do not have a uniform format and it is difficult to compare the variables in each domain. On setting the maximal, minimal of optimal thresholds interactively through 
the characteristics of each variable and the user's references, we standardize any variable $x_{i j}$ in domain $i$.

For the-bigger-the better variable (type I):

$$
\mu_{i j}=\frac{x_{i j}-x_{i j, \min }}{x_{i j, \max }-x_{i j, \min }}
$$

For the-smaller-the- better variable (type II):

$$
\mu_{i j}=\frac{x_{i j, \text { max }}-x_{i j}}{x_{i j, \max }-x_{i j, \min }} .
$$

\section{Methodology}

\subsection{Single variable integration}

In each domain, there are no less than two single variables and each variable has a different contribution or influence on the total performance of domain. Here we assume that the importance of an individual variable is specified as a proportion of deviation of the given-domain variable to the cumulative deviations of all variables. For domain $i$ with $m$ variables, the deviations of variable $j$ over $n$ years can be given as $\sum_{l=1}^{n}\left|\mu_{i j}(t)-\mu_{i j}(l)\right| w_{j}$, and, therefore, the solution of the weight vector for domain $i$ refers to the optimization access [18]:

$$
\left\{\begin{array}{l}
\max \sum_{j=1}^{m} \sum_{l=1}^{n}\left|\mu_{i j}(t)-\mu_{i j}(l)\right| w_{j} \\
\text { s.t. } \quad w_{j} \geq 0, j \in m, \sum_{j=1}^{m} w_{j}^{2}=1
\end{array}\right.
$$

\begin{tabular}{|c|c|c|c|c|c|c|c|c|c|c|c|c|c|c|}
\hline \multirow[b]{2}{*}{ Sym } & \multicolumn{11}{|c|}{ Variable statistics } & \multirow[b]{2}{*}{$\operatorname{Max}$} & \multirow[b]{2}{*}{ Min } & \multirow[b]{2}{*}{ Weigh } \\
\hline & 2000 & 2001 & 2002 & 2003 & 2004 & 2005 & 2006 & 2007 & 2008 & 2009 & 2010 & & & \\
\hline$x_{1}$ & 31.5 & 32.3 & 34.6 & 36.0 & 36.8 & 38.7 & 40.1 & 42.3 & 44.7 & 47.3 & 50.8 & 75 & 20 & 0.042 \\
\hline$x_{2}$ & 4871.5 & 4953 & 5031 & 5101 & 5168 & 5269 & 5317 & 5435 & 5549 & 5734 & 5913 & 7500 & 800 & 0.270 \\
\hline$x_{3}$ & 0.265 & 0.273 & 0.287 & 0.294 & 0.307 & 0.325 & 0.369 & 0.383 & 0.397 & 0.411 & 0.419 & 0.5 & 0.15 & 0.130 \\
\hline$x_{4}$ & 4.7 & 5.2 & 4.3 & 3.8 & 4.3 & 3.9 & 3.5 & 3.7 & 3.8 & 4.0 & 3.9 & 7 & 0 & 0.081 \\
\hline$x_{5}$ & 14.36 & 14.79 & 15.24 & 14.86 & 14.71 & 14.62 & 14.58 & 14.76 & 14.82 & 14.91 & 15.06 & 40 & 5 & 0.006 \\
\hline$x_{6}$ & 3.68 & 3.43 & 3.21 & 2.60 & 2.25 & 1.69 & 1.43 & 1.75 & 1.92 & 2.14 & 2.33 & 4 & 1 & 0.338 \\
\hline$x_{7}$ & 67 & 73 & 75 & 68 & 62 & 64 & 67 & 73 & 70 & 66 & 63 & 100 & 20 & 0.133 \\
\hline $\mathrm{x}_{8}$ & 2.41 & 2.70 & 3.08 & 3.49 & 4.11 & 4.54 & 4.73 & 5.02 & 5.09 & 5.16 & 5.34 & 8 & 1.5 & 0.161 \\
\hline$x_{9}$ & 32.5 & 32.9 & 34.7 & 35.6 & 36.4 & 36.9 & 38.1 & 39.3 & 41.7 & 43.9 & 45.5 & 60 & 20 & 0.142 \\
\hline$x_{10}$ & 103.65 & 109.73 & 118.41 & 122.61 & 135.17 & 142.85 & 137.68 & 134.79 & 131.75 & 128.47 & 131.64 & 150 & 100 & 0.379 \\
\hline$x_{11}$ & 2128 & 2407 & 2876 & 3208 & 3519 & 3503 & 3729 & 4133 & 4371 & 4408 & 4576 & 6000 & 1000 & 0.318 \\
\hline$x_{12}$ & 40.6 & 39.2 & 38.4 & 37.1 & 35.3 & 34.4 & 34.1 & 32.0 & 31.1 & 29.1 & 28.4 & 50 & 15 & 0.083 \\
\hline$x_{13}$ & 9.3 & 14.1 & 16.0 & 18.7 & 21.3 & 19.7 & 22.9 & 24.3 & 25.7 & 26.2 & 27.3 & 40 & 5 & 0.131 \\
\hline$x_{14}$ & 1306 & 1466 & 1627 & 1807 & 1929 & 2161 & 2245 & 2287 & 2317 & 2393 & 2468 & 4500 & 1000 & 0.047 \\
\hline$x_{15}$ & 2.71 & 3.00 & 6.65 & 8.31 & 6.63 & 8.31 & 10.12 & 9.36 & 9.94 & 10.36 & 11.44 & 15 & 0 & 0.422 \\
\hline$x_{16}$ & 4.8 & 5.2 & 6.8 & 8.9 & 11.3 & 12.5 & 13.1 & 13.6 & 14.0 & 14.7 & 15.3 & 20 & 0 & 0.317 \\
\hline$x_{17}$ & 8.68 & 8.92 & 9.35 & 9.60 & 10.03 & 11.11 & 11.79 & 12.34 & 12.96 & 13.47 & 14.12 & 15 & 3 & 0.147 \\
\hline$x_{18}$ & 4.7 & 4.3 & 4.3 & 4.0 & 3.3 & 2.6 & 2.4 & 2.1 & 2.0 & 2.3 & 2.1 & 6 & 0 & 0.120 \\
\hline$X_{19}$ & 43.9 & 56.8 & 62.7 & 74.9 & 80.6 & 90.9 & 96.8 & 98.4 & 98.9 & 99.2 & 99.8 & 100 & 0 & 0.243 \\
\hline$x_{20}$ & 4.72 & 3.61 & 3.74 & 3.33 & 3.29 & 3.29 & 3.13 & 2.98 & 2.81 & 2.73 & 2.69 & 5 & 0 & 0.023 \\
\hline$x_{21}$ & 63.5 & 61.7 & 56.7 & 52.8 & 49.1 & 48.2 & 49.3 & 44.5 & 42.7 & 43.1 & 40.4 & 75 & 30 & 0.092 \\
\hline$x_{22}$ & 18 & 15 & 12 & 9 & 11 & 10 & 12 & 11 & 11 & 10 & 10 & 25 & 5 & 0.098 \\
\hline$x_{23}$ & 78.1 & 72.4 & 65.2 & 57.4 & 53.8 & 45.6 & 42.4 & 38.7 & 37.5 & 35.8 & 34.1 & 85 & 25 & 0.116 \\
\hline$x_{24}$ & 10.03 & 9.03 & 8.09 & 7.08 & 7.01 & 5.76 & 5.25 & 5.01 & 4.86 & 4.72 & 4.69 & 15 & 0 & 0.085 \\
\hline$x_{25}$ & 21.5 & 22.7 & 22.9 & 23.7 & 25.8 & 28.6 & 33.4 & 36.7 & 38.2 & 39.7 & 41.3 & 100 & 0 & 0.024 \\
\hline$x_{26}$ & 66.82 & 74.39 & 74.02 & 73.08 & 70.24 & 69.62 & 64.13 & 63.32 & 66.3 & 70.4 & 72.1 & 100 & 30 & 0.052 \\
\hline
\end{tabular}

And, thus, it reaches the weight expression as:

Table 3. Data acquisition and performance variables for Component $A$.

Source: the reference variables are directly collected from 'Beijing Statistical Yearbook (2001 2010)', "Beijing Environment Situation Bulletin (2000 2010)", "Report of Beijing Traffic Noise Situation Survey (2006, 2010)", etc. 


\begin{tabular}{|c|c|c|c|c|c|c|c|c|c|c|c|c|c|c|}
\hline \multirow{2}{*}{ Sym } & \multicolumn{11}{|c|}{ Variable statistics } & \multirow[b]{2}{*}{ Max } & \multirow[b]{2}{*}{ Min } & \multirow{2}{*}{ Weigh } \\
\hline & 2000 & 2001 & 2002 & 2003 & 2004 & 2005 & 2006 & 2007 & 2008 & 2009 & 2010 & & & \\
\hline$x_{27}$ & 80.68 & 81.76 & 85.43 & 82.98 & 87.0 & 90.68 & 91.37 & 91.84 & 92.04 & 93.42 & 94.15 & 120 & 70 & 0.154 \\
\hline$x_{28}$ & 6.29 & 7.49 & 7.82 & 10.51 & 10.30 & 10.32 & 10.46 & 10.55 & 11.07 & 11.66 & 12.32 & 30 & 5 & 0.044 \\
\hline$x_{29}$ & 29.02 & 30.90 & 29.16 & 35.38 & 32.48 & 29.18 & 28.87 & 28.46 & 28.14 & 27.63 & 26.28 & 45 & 10 & 0.322 \\
\hline$x_{30}$ & 2.80 & 2.83 & 2.84 & 2.84 & 2.93 & 3.01 & 3.12 & 3.29 & 3.33 & 3.51 & 3.59 & 5 & 1 & 0.103 \\
\hline$x_{31}$ & 7.3 & 7.5 & 8.9 & 9.5 & 11.7 & 13.6 & 15.4 & 19.1 & 20.7 & 21.2 & 23.4 & 35 & 5 & 0.110 \\
\hline$x_{32}$ & 45.1 & 49.3 & 46.7 & 53.8 & 59.7 & 55.6 & 63.9 & 65.0 & 66.3 & 67.9 & 69.0 & 100 & 30 & 0.191 \\
\hline$x_{33}$ & 5.3 & 5.5 & 6.4 & 7.1 & 7.8 & 8.5 & 9.6 & 9.8 & 10.2 & 10.8 & 11.6 & 20 & 5 & 0.076 \\
\hline$x_{34}$ & 26.5 & 25.7 & 25.5 & 23.2 & 26.0 & 28.1 & 30.1 & 33.1 & 35.6 & 37.3 & 39.5 & 70 & 15 & 0.020 \\
\hline$x_{35}$ & 21.5 & 19.6 & 22.5 & 21.2 & 27.4 & 29.5 & 32.3 & 34.5 & 36.3 & 35.8 & 38.4 & 40 & 10 & 0.217 \\
\hline$x_{36}$ & 0.75 & 0.72 & 0.69 & 0.73 & 0.79 & 0.85 & 0.83 & 0.91 & 0.93 & 0.95 & 0.91 & 1.2 & 0.5 & 0.114 \\
\hline$x_{37}$ & 21.3 & 18.7 & 13.6 & 9.7 & 13.7 & 10.7 & 10.9 & 8.8 & 9.3 & 8.7 & 8.6 & 30 & 5 & 0.443 \\
\hline$x_{38}$ & 37 & 39 & 44 & 46 & 51 & 55 & 62 & 56 & 65 & 71 & 78 & 100 & 30 & 0.075 \\
\hline$x_{39}$ & 22.7 & 28.6 & 31.2 & 33.5 & 42.7 & 38.9 & 31.4 & 28.3 & 33.4 & 35.7 & 38.9 & 60 & 15 & 0.131 \\
\hline$x_{40}$ & 16.2 & 17.1 & 22.4 & 23.6 & 21.8 & 25.7 & 26.5 & 23.9 & 25.7 & 28.9 & 27.1 & 40 & 8 & 0.185 \\
\hline$x_{41}$ & 14 & 16 & 19 & 22 & 19 & 23 & 17 & 19 & 17 & 21 & 22 & 30 & 10 & 0.255 \\
\hline$x_{42}$ & 8.7 & 8.3 & 7.7 & 8.2 & 7.9 & 8.1 & 9.4 & 9.3 & 9.7 & 10.1 & 10.6 & 15 & 0 & 0.026 \\
\hline$x_{43}$ & 5 & 11 & 15 & 19 & 22 & 26 & 35 & 38 & 42 & 46 & 51 & 80 & 0 & 0.038 \\
\hline$x_{44}$ & 43 & 52 & 68 & 74 & 80 & 89 & 100 & 100 & 100 & 100 & 100 & 100 & 0 & 0.317 \\
\hline$x_{45}$ & 0.5 & 0.65 & 0.75 & 1.23 & 1.15 & 1.61 & 1.38 & 1.84 & 1.73 & 1.79 & 1.88 & 2 & 0.35 & 0.179 \\
\hline$x_{46}$ & 5.32 & 5.07 & 4.85 & 4.21 & 4.57 & 3.76 & 3.23 & 2.69 & 2.55 & 2.47 & 2.31 & 8 & 0 & 0.1757 \\
\hline$x_{47}$ & 0.21 & 0.25 & 0.33 & 0.36 & 0.31 & 0.27 & 0.29 & 0.24 & 0.21 & 0.19 & 0.18 & 0.5 & 0.1 & 0.6685 \\
\hline$x_{48}$ & 5.75 & 7.25 & 8.88 & 14.25 & 17.13 & 21.75 & 28.63 & 30.25 & 33.29 & 35.73 & 38.97 & 100 & 0 & 0.0432 \\
\hline$x_{49}$ & 5.3 & 5.5 & 6.4 & 7.1 & 7.8 & 8.5 & 9.6 & 9.8 & 10.1 & 11.7 & 13.2 & 20 & 5 & 0.0635 \\
\hline$x_{50}$ & 31.5 & 30.4 & 34.0 & 28.7 & 30.2 & 33.1 & 41.7 & 35.6 & $\begin{array}{l}42.6 \\
\end{array}$ & 45.1 & 49.9 & 100 & 0 & 0.0491 \\
\hline
\end{tabular}

Table 4. Data acquisition and performance variables for Component B.

Source: the reference variables are directly collected from 'Beijing Statistical Yearbook (2000 2010)', 'Beijing Transport Development Annual Report (2000-2010)', 'Report of the Second Urban Comprehensive Traffic Survey in Beijing (2000), 'Report of the Third Comprehensive Traffic Survey in Beijing (2007)', 'Report of the Forth Comprehensive Traffic Survey in Beijing (2010)', etc.

$$
\left\{w_{i j}\right\}=\frac{\sum_{l=1}^{n}\left|\mu_{i j}(t)-\mu_{i j}(l)\right|}{\sum_{j=1}^{m} \sum_{l=1}^{n}\left|\mu_{i j}(t)-\mu_{i j}(l)\right|}
$$

Finally, the performance of domain $i$ is represented through the weighted linear integrations of all deviations of $m$ variables. That is, mathematically:

$$
P_{i}=\sum_{j=1}^{m} w_{i j} \mu_{i j}
$$

\subsection{Domain Weight Estimation with Paired Comparison Matrix [19]}

To form the paired comparison matrix for weighting the importance of each domain in two components, different stakeholders are interviewed in order to reflect their personal opinions and feelings on each domain, and each component pair $(m, n)$ as a comparison judgment $r_{m n}(m, n=1,2, \ldots, 4)$ in response to the importance ratio of variables $m$ and $n$ is developed by assigning a number from 
Satty's nine-point scale, where, 1 represented "equal importance", 3 denoted "moderate importance", 5 stood for "strong importance", 7 meant "very strong importance", and 9 was "extreme importance", representing the ratio of their importance contributing to their upper-level component [20].

Thus, each comparison value $a_{i j}$ equals to $w_{i} / w_{j}$ exactly, if the exact weights vector $w=\left(w_{1}, \ldots, w_{n}\right)^{\mathrm{T}}$ are known. In this case, a pairwise comparison matrix $A$ can be written as:

$$
A=\left(\begin{array}{cccc}
1 & a_{12} & \cdots & a_{1 n} \\
a_{21} & 1 & & a_{2 n} \\
\vdots & & \ddots & \vdots \\
a_{n 1} & a_{n 2} & \cdots & 1
\end{array}\right)=\left(\begin{array}{cccc}
1 & w_{1} / w_{2} & \cdots & w_{1} / w_{n} \\
w_{2} / w_{1} & 1 & & w_{2} / w_{n} \\
\vdots & & \ddots & \vdots \\
w_{n} / w_{1} & w_{n} / w_{2} & \cdots & 1
\end{array}\right)
$$

For an input matrix $\mathrm{A} \in \mathrm{R}^{m \times n}$, with rank $\mathrm{r}, \mathrm{r} \leq \min (m$, $n)$, the SVD of A can be written in the form of [21]:

$$
\mathrm{A}=\mathrm{UDV}^{\mathrm{T}}=\sum_{i=1}^{k} \sigma_{i} u_{i} v_{i}^{T}
$$

where $D=\left[\operatorname{diag}\left(\sigma_{1}, \sigma_{2}, \cdots, \sigma_{r}\right)\right.$, O] or its transposition determined by $m<n$ or $m>n$, while $\mathrm{O}$ is zero matrix and $0<\sigma_{k} \leq \cdots \leq \sigma_{2} \leq \sigma_{1} \in R$. These $\sigma_{i}(i=1,2, \ldots, r)$ are denoted as the singular values of matrix $A$. $U$ and $V$ are two orthogonal matrices with $U=\left[u_{1}, u_{2}, \ldots, u_{m}\right] \in R^{m \times m}$ and $V=$ $\left[v_{1}, v_{2}, \ldots, v_{n}\right] \in \mathrm{R}^{n \times n}$. Here, $u_{i}$ and $v_{i}$ are termed the left and right singular vectors of $A$, respectively, in response to singular value $i$.

Let a pairwise comparison matrix $A$ be given, where $a_{i j}=1 / a_{j i}$ and $a_{i j}=a_{i k} / a_{j k}$ for any $i, j$, and $k$, thus it is a positive matrix with reciprocality and consistency and its weight satisfies [22]:

$$
W_{i}=\frac{u_{i}}{\sum_{j=1}^{n} u_{j}}=\frac{\frac{1}{v_{i}}}{\sum_{j=1}^{n} \frac{1}{v_{j}}}
$$

But if $a_{i j}$ is not always equal to $a_{i k} / a_{j k}$ for all $i, j$, and $k$, the consistency of matrix $A$ is acceptable, and the determination of the weight vector could be converted into [22]:

$$
\left\{\begin{array}{l}
\min \left[\mathrm{D}(u \| W)+\mathrm{D}\left(\frac{1}{v} \| W\right)\right] \\
\text { s.t. } \quad \sum_{i=1}^{n} W_{i}=1
\end{array}\right.
$$

That is, the weight vector is expanded into:

$$
W_{i}=\frac{u_{i}+\frac{1}{v_{i}}}{\sum_{j=1}^{n}\left(u_{j}+\frac{1}{v_{i}}\right)}
$$

\subsection{Consistency Improvement of Paired} Comparison Matrix [19]

For a paired comparison matrix $A$, its consistency should be checked through the $C R$ value, according to Satty's formula [20]. If $C R>0.1$, the matrix $A$ is invalid in consistency and should be adjusted repeatedly until $C R \leq 0.1$.

Generally, their distance between two real numbers $x$ and $y$ is defined as:

$$
d(x, y)=\frac{|x-y|}{\max (x, y)}
$$

For a pairwise comparison matrix with low level of inconsistency, the distance between each row vector $e_{i}$ and the $W$ vector corresponding to $\lambda_{\max }$ is given by [23]:

$$
d_{i}=\frac{1}{n} \sum_{j=1}^{n} \frac{\left|e_{i}^{j}-W_{j}\right|}{\max \left(e_{i}^{j}, W_{j}\right)},
$$

and all row vectors fluctuate around $W$ and the fluctuation amplitude also reflects its level of inconsistency. Obviously, the row vector with the longest distance to $W$ has the most significant effect on the matrix consistency. Subsequently, the row $L$ of significant element $e_{L H}$ in inconsistency 
matrix $A$ could be identified through $d_{L}=\max \left(d_{i}\right)$. Repeatedly, the distance $d_{L i}$ between $e_{L}$ and $W$ could be given by Eq. (13) to identify the maximum $d_{L H}=\max \left(d_{L i}\right)$ and determine the column $H$ of significant element $e_{L H}$.

$$
d_{L i}=\frac{\left|e_{L}^{i}-W_{i}\right|}{\max \left(e_{L}^{i}, W_{i}\right)}
$$

If the average $\bar{e}_{L H}$ equals to $\frac{1}{n} \sum_{j=1}^{n} e_{L j} / e_{H j}$, thus $e_{L H}$ could be modified into:

$$
e_{L H}^{*}=\frac{1}{2}\left(\bar{e}_{L H}+\frac{1}{\bar{e}_{L H}}\right)
$$

The element $e_{H L}$ in matrix $A$ is then replaced by $1 / e_{L H}^{*}$ and the consistency of pair comparison matrix $A$ is improved. Thus, the weigh vector could be determined by Eq. (8) or (10).

\subsection{Performance Indicator Profile}

Thereafter, the total contribution of specific variables and domains to the performance of a specific transportation planning project and operation could be measured by the single variables integrated from domains to components. Particularly, the performances of component $A$ (urban system) and component B (transportation network) can be statistically re-weighted through the domain performances as:

$$
I_{\text {urb, tra }}=\sum_{i} W_{i}^{\mathrm{urb}, \text { tra }} P_{i}^{\mathrm{urb}, \text { tra }}
$$

To measure the overall performance of transportation network quantitatively, an indicator, Transportation Adaptability Performance Index $(T A P I)$, is formatted to monitor and keep track of the planning process in the interval and help understand precisely how the implementation process is going over time, on the assumption that the performance of transportation planning and operation could be quantified by the integration and combination of the single variable.

Here TAPI is specified as the ratio of performance differences ( $I_{\text {urb }} \& I_{\text {tra }}$ ) of the two components over $t$, and it yields a generalized ordered model as [19]:

$$
\begin{aligned}
& \Delta_{\mathrm{TAPI}}=\theta \cdot \sqrt{\left|\left(I_{\text {tra }}^{t}-I_{\text {tra }}^{0}\right) /\left(I_{\text {urb }}^{t}-I_{\text {urb }}^{0}\right)\right|} \\
& \theta=\frac{\left(I_{\text {tra }}^{t}-I_{\text {tra }}^{0}\right) \cdot\left(I_{\text {urb }}^{t}-I_{\text {urb }}^{0}\right)}{\left|\left(I_{\text {tra }}^{t}-I_{\text {tra }}^{0}\right) \cdot\left(I_{\text {urb }}^{t}-I_{\text {urb }}^{0}\right)\right|}
\end{aligned}
$$

In the context of Eq. (16), $\mathrm{I}_{\text {urb }}^{t} \neq \mathrm{I}_{\text {urb }}^{0}$ and $\mathrm{I}_{\text {tra }}^{t} \neq \mathrm{I}_{\text {tra }}^{0}$ mean that the implementation of transportation planning comes into effect and the performance of two components are generally enhanced over a certain development period. Obviously, $\theta=1$ or -1 that helps check whether the performances of the transportation network are adapted to the demand of the social and economic development in the form of the similar increasing or decreasing trend during the period of $0 \sim t$.

\section{Results and Findings}

\subsection{Single Variable Assessment}

By Eqs. (1) - (2), the single variable in each domain is normalized into a comparable standardized value. The deviation of a given variable in any domain could be counted out and the weight vectors of domains are to be acquired by Eq. (4). Consequently, the performances of the 8 domains are quantitatively evaluated by Eq. (5), respectively, as shown in Figure 1. 

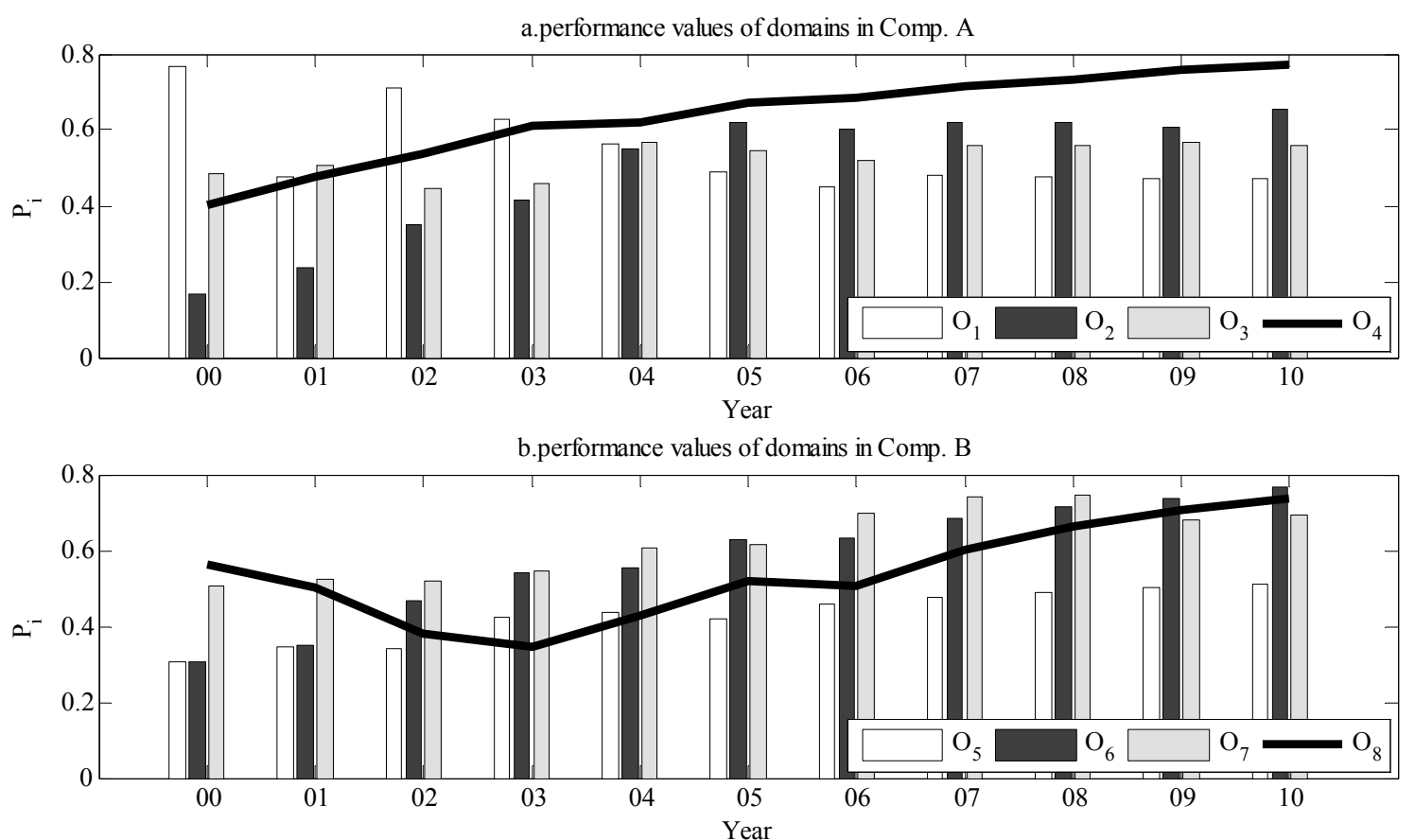

Figure 1. Performances of eight evaluation domains.

Clearly, we can see most performance domains experienced an increasing process during 20002010. However, the scores of social development declined year by year and, more seriously, the yearly performance of this domain scored under 0.5 after 2005, which provides an urgent alarm to promote the social equality and balance of resources, income and wealth. Moreover, the life quality domain scored much lower than expected, due to the inflation of currency, and most interviewers feel the increasing burdens of daily expenditures. We also see a significant improvement in the ecological environment.

The transportation network plays an important role in promoting the development of society and economy. The transportation network has made a significant progress in Beijing metropolitan region, especially when it comes to public transport (BRT system, low bus and subway fares, etc.). As for the domains of $\mathrm{O}_{5} \sim \mathrm{O}_{8}$, the measured performance values also increased over these years, and the performance score of efficiency even reached 0.7687 in 2010. But the reliability of the transportation network still scored below 0.52 , and this could be because of the lack of effective use of the present transportation network and facilities. Moreover, both operation and safety scored under 0.74 and have a great scope for further improvement.

\subsection{Estimation of Domain Weight}

The performance of components $\mathrm{A}$ and $\mathrm{B}$ can be perceived and measured through the weighted integration of domains using Eq. (15), and the domain weights are approximated by the approach of analytic hierarchy process. Firstly, a total of 25 cross-country representations with 5 in Beijing, 3 in Xi'an, 2 in Nanjing, 6 in Harbin, 3 in Shenzhen, 4 in Dalian and 2 in Kunming were invited to participate in an interview through email and provide the relative importance of values in the upper triangular matrix $R_{\text {urb, trans }}=R^{4 \times 4}=\left[r^{4 \times 4}\right]$. The selected interviews are distributed among the three levels: five interviews with planning agencies, four with planning practitioners, seven with manager groups (e. g., governmental departments, traffic management, transit companies.), and nine 
interviews with normal travelers and system users (different occupations, age, orientation and income).

A survey and a brief description of it were appended to the interviews, including the goals, contents, and standards. All interviews were recorded. In the end, 4 individuals did not respond to the invitation and a total of 3 did not give the judging value among the rest 21 responses, thus a total of 18 valid samples were received.

\begin{tabular}{|c|c|c|}
\hline Component & $\mathrm{A}$ & $\mathrm{B}$ \\
\hline Matrix & $R_{\text {urb }}^{0}$ & $R_{\text {trans }}^{0}$ \\
\hline $\mathrm{A}$ & {$\left[\begin{array}{cccc}1 & 3 & 4 & \frac{1}{2} \\
\frac{1}{3} & 1 & 2 & \frac{1}{3} \\
\frac{1}{4} & \frac{1}{2} & 1 & \frac{1}{5} \\
2 & 3 & 5 & 1\end{array}\right]$} & {$\left[\begin{array}{cccc}1 & \frac{1}{2} & 1 & 3 \\
2 & 1 & \frac{1}{3} & 4 \\
1 & 3 & 1 & 5 \\
\frac{1}{3} & \frac{1}{4} & \frac{1}{5} & 1\end{array}\right]$} \\
\hline$\lambda_{\max }^{0}$ & 4.0566 & 4.2895 \\
\hline$C l^{0}$ & 0.0210 & 0.1084 \\
\hline$R I$ & 0.89 & $0.1218>0.1$ \\
\hline$C R$ & $0.0236<0.1$ & 0.89 \\
\hline
\end{tabular}

Table 5. Domain matrixes and consistency.

Then we obtained two pair comparison matrixes $R_{\mathrm{urb}}^{0}$ and $R_{\text {tra }}^{0}$ (see Table 5) after synthesizing each expert's opinion [19]. For Component $\mathrm{A}$, the check of $\mathrm{Cl}=$ $0.0236<0.1$ and $a_{i j} \neq a_{i k} / a_{j k}$ means the consistency of matrix $R_{\text {urb }}^{0}$ was acceptable. By Eq. (7), $R_{\text {urb }}^{0}$ was divided into a diagonal matrix $D$ and two unitary matrixes $U$ and $V$ in the form of $U D V^{T}$ :
Thus, the weight of $R_{\text {urb }}^{0}$ yields $W_{\text {urb }}=[0.2762$, $0.1372,0.0861,0.5005]^{T}[19]$.

Unfortunately, the paired comparison matrix $R_{\text {tra }}^{0}$ of Component $B$ is inconsistent, and needs to improve its consistency through modifying the element in matrix. From Table 5, we can see $\lambda_{\max }=4.2895$, and the corresponding eigenvector $W_{\text {tra }}^{0}=[0.2343,0.2708,0.4248$, $0.0702]^{T}$. Subsequently, the distance between each normalized column vector $e_{i}$ and $W_{\text {tra }}^{0}$ could be determined by Eq. (12) as $d_{i}=[0.2432$, $0.3377,0.2756,0.0793]^{T}$. Obviously, the second column $e_{2}$ has the longest distance to $W_{\text {tra }}^{0}$. Then the distance between the normalized $e_{2}=$ $[0.1053,0.2105,0.6316,0.0526]^{T}$ and $W_{\text {tra }}^{0}$ is recalculated and we reach $[0.5506,0.2227$, $0.3274,0.2507]^{T}$ [19]. Therefore, $e_{21}$ is the significant element to be modified.

According to Eq. (14), the average $\bar{e}_{21}$ is $\frac{1}{4} \sum_{j=1}^{4} \frac{e_{2 j}}{e_{1 j}}=\frac{1}{4}\left(\frac{2}{1}+\frac{1}{\frac{1}{2}}+\frac{\frac{1}{3}}{1}+\frac{4}{3}\right)=1.4167$, and could be further approximated as $e_{21}^{*}=\frac{1}{2}\left(\bar{e}_{21}+\frac{1}{\bar{e}_{21}}\right)=$ $\frac{1}{2}\left(1.4167+\frac{1}{1.4167}\right)=1.0613$ and thus $e_{12}^{*}$ is revised into 0.9422. Obviously, the modified matrix has $C R$ $=0.0578<0.1$ with satisfied consistency (Table 6). In the end, the weight vector of Component $B$ is determined as $W_{\text {tra }}^{1}=[0.2731,0.2303,0.4227$, $0.0739]^{T}$ accounting to $\lambda_{\max }^{1}=4.1544$.

$$
R_{\text {urb }}^{0}=\left[\begin{array}{cccc}
-0.6039 & -0.7571 & 0.2452 & -0.0442 \\
-0.2675 & -0.0959 & -0.8914 & 0.3531 \\
-0.1369 & 0.0554 & -0.3337 & -0.9310 \\
-0.7382 & 0.6438 & 0.1843 & 0.0808
\end{array}\right]\left[\begin{array}{cccc}
8.4366 & 0 & 0 & 0 \\
0 & 0.7013 & 0 & 0 \\
0 & 0 & 0.3956 & 0 \\
0 & 0 & 0 & 0.0107
\end{array}\right]\left[\begin{array}{ccccc}
-0.2612 & 0.7307 & 0.5894 & 0.2244 \\
-0.5171 & -0.5819 & 0.5819 & -0.2355 \\
-0.8035 & 0.0774 & -0.5415 & 0.2349 \\
-0.1371 & 0.3485 & -0.1440 & -0.9160
\end{array}\right]^{T}
$$




\begin{tabular}{|c|c|c|c|c|c|c|c|}
\hline & $R_{\text {tra }}^{1}$ & & & $\mathrm{Cl}^{1}$ & $R I^{1}$ & $n$ & $C R^{1}$ \\
\hline 1 & 0.9422 & 1 & & \multirow{4}{*}{0.0514} & \multirow{4}{*}{0.89} & \multirow{4}{*}{4} & \multirow{4}{*}{$\begin{array}{l}0.0578 \\
<0.1\end{array}$} \\
\hline 1.0613 & 1 & & 4 & & & & \\
\hline 1 & 3 & & 5 & & & & \\
\hline$\frac{1}{3}$ & $\frac{1}{4}$ & $\frac{1}{5}$ & 1 & & & & \\
\hline
\end{tabular}

Table 6. Consistency improvement items of $R_{\text {tra. }}$.

\subsection{TAPI Measure Determination}

As soon as the determination of the domain weights had been performed, we yielded the weighted combination lurb and Itra yearly by Eq. (15) as performances of multiple social and economic development in urban metropolitan region and operations of transportation network, as Figure 2 shows. Obviously, the inflection point appeared in 2006 and 2009. The performance of the transportation network scored below that of the urban system over 2000-2006 because of the accelerated urbanization along with the explosive economic growth. With the coming of the 2008 Beijing Olympic Games, the government invested billions of dollars to increase the capacity and service of airports, transit systems and major roads, especially safer and more efficient subway lines, which helped to improve the overall performance; however, the operation performances of these two systems tended to take a "balanced" approach in 2009 and 2010, and they got approximately the same score.

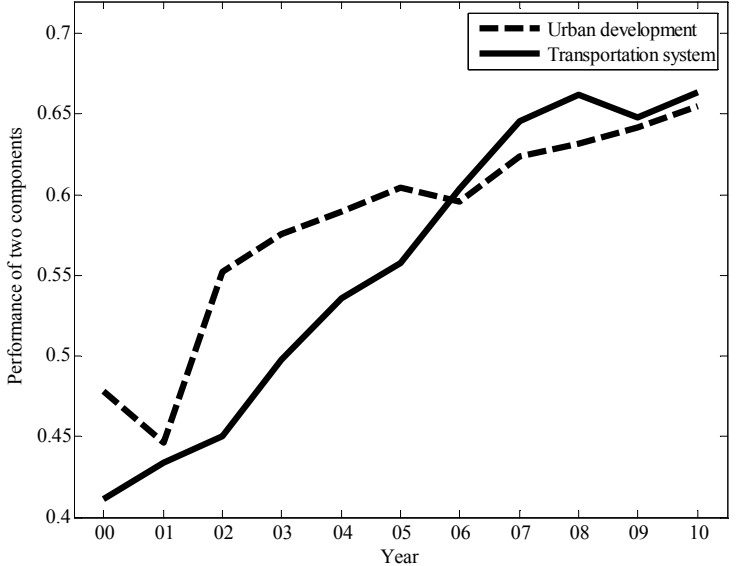

Figure 2. Performances of both Components A and B.

Thereafter, the transportation adaptability performance index and $\theta$ over 2000-2010, which are derived from Eq. (16), are expressed in terms of

It is obvious that the change of the TAPI value has undergone a similar regulation or feature over time, as shown in Figure 2. In addition, $T A P I_{01-02}$ measured in 0.150 implies that transportation infrastructure construction and maintenance were lagged behind the requirement of modern social-economic development. This could be explained through the poor transportation network in reliability, efficiency, operation and safety performance caused by few care policies and limited investment within these years. However, the oversize values of $\mathrm{TAPl}_{02-03}$, $T A P I_{03-04}$ and $T A P I_{05-06}$ also indicate that deep concerns have arisen and extensive investment has been made. When transport systems are efficient, they provide economic and social opportunities eventually; at the same time, excessive measures, however, can also bring unavoidable and sharp change in transportation performance, such as the significant increasing of $T_{A P I_{05-06}}$.

$$
\left[\begin{array}{c}
A P I \\
\theta
\end{array}\right]=\left[\begin{array}{cccccccccc}
0.725 & 0.150 & 2.078 & 2.779 & 1.437 & 5.337 & 1.503 & 1.948 & 1.378 & 1.157 \\
-1 & 1 & 1 & 1 & 1 & -1 & 1 & 1 & -1 & 1
\end{array}\right]
$$




\section{Conclusions}

This paper discusses the procedure and findings from research that lead to develop a quantitative methodology and tool for metropolitan transportation agencies to quantify and evaluate the performance of transportation plans during the implementation process. The research is applied to the Beijing metropolitan region as an illustrative study. 50 performance variables linked to social, economic and environmental goals are developed and divided into 8 domains in 2 components, and a weighted multi-criteria combination methodology is used to measure the adaptability index values of different periods, in which the domain weight is estimated from the paired comparison matrix with acceptable consistency through the singular value decomposition approach. Specially, the paired comparison matrix is improved by the modification of the significant element, if its consistency is unacceptable. This methodology is implemented in the form of a user-friendly analysis tool for transportation planning practitioners and can help find the potential problems in transportation plans, implementation processes and fund allocations over a much broader scope and agenda.

There are some important notes from this study and it is very important, but very difficult, to choose and process the effective performance variables over a long period of time for trends. Thus, it is recommended that future research lies in exploring an intelligent data processing technique. How can bridge transportation planning and implementation process be reengineered to be conducted within a multidisciplinary set of perspectives (e.g., energy use, traffic equity, community development)? There is a need for continued or more in-depth discussion on certain topics.

The findings and results show that to promote the transportation planning systematically, whether as a strategy for achieving sustainable urban goals or for other items, a policy maker should recognize the demands from different stakeholders [24]. As for metropolitans in China, more attention has been paid on road expansion and facilities construction as well as on the social (economic) environment improvement; however, the physical environment and human oriented transportation issues have been always neglected, just as in the capital Beijing, characterized by low performance of variables in the ecological environment and traffic opinions. Although it may be one of the most challenging issues to solve, it is apparent that the authority in charge of implementing the plans must have a better understanding and make emphasis on setting up new planning projects. At this stage, the most urgent need is to establish stronger connections between transportation and the urban system; this has not yet been accepted by national metropolitan planning organizations, state transportation agencies, and local counties in China.

\section{Acknowledgements}

This research was supported by the Special Fund for the Basic Scientific Research of Central Colleges, Chang'an University (No. CHD2012JC023). Sections 3.2, 3.3 and 4.2 are part of the Ph.D thesis of Y.G. Wang, separately, and many thanks are given to the supervisor, Prof. Y.L. Pei, in Harbin Institute of Technology, China. We also acknowledge the editors and anonymous reviewers for their detailed suggestions, precise comments and continuous help which lead to the belief that their dedication contributes to this research work and it would not have been feasible without their support. 


\section{References}

[1] A. Shariat Mohaymany, M. Babaei, "An approximate reliability evaluation method for improving transportation network performance", Transport, vol. 25, no. 2, pp. 193-202, 2010

[2] J. S. Miller, L. A. Hoel, T. F. Dalton, D. R. McCray, "Linking transportation planning to program implementation", Journal of Urban Planning and Development, vol. 134, no. 2, pp, 88-95, 2008

[3] M. E. Ozbek, J. M. De la Garza, "Comprehensive evaluation of Virginia Department of Transportation's experience with its first performance-based roadmaintenance contract", Journal of Transportation Engineering, vol. 137, no. 12, pp. 845-854, 2011

[4] H. Wallbaum, S. Krank, R. Teloh, "Prioritizing sustainability criteria in urban planning processes: Methodology application", Journal of Urban Planning and Development, vol. 137, no. 1, pp, 20-28, 2011

[5] S. Handy, "Regional transportation planning in the US: an examination of changes in technical aspects of the planning process in response to changing goals", Transport Policy, vol. 15, no. 2, pp.113-126, 2008

[6] T. L. Ramani, J. Zietsman, W. E. Knowles, L Quadrifoglio, "Sustainability enhancement tool for state departments of transportation using performance measurement", Journal of Transportation Engineering, vol. 137, no. 6, pp. 404-415, 2011

[7] S. B. Gayle, "Performance-based planning: a practitioner's view of transportation planning in the 21st century", ITE Journal - Institute of Transportation Engineers, vol. 79, no. 9, pp. 48-50, 2009

[8] L. Krpan, "Analysis of implementing spatial and traffic studies in the development of physical planning documents of Primorje-Gorski Kotar County", Promet Traffic \& Transportation, vol. 23, no. 1, pp. 71-79, 2011

[9] S. Samberg, A. Bassok, S. Holman, "Method for evaluation of sustainable transportation: Toward a comprehensive approach", Transportation Research Record, no. 2242, pp. 1-8, 2011
[10] Y. Li, H. L. Guo, H. Li, G. H. Xu, Z. R. Wang, C. W. Kong, "Transit-oriented land planning model considering sustainability of mass rail transit", Journal of Urban Planning and Development, vol. 136, no. 3, pp. 243248, 2010

[11] H. W. Fu, R. Mayhew, L. Bailey, L. Shoup, "Innovative coordination between states, metropolitan planning organizations, and tribes in transportation planning", Transportation Research Record, no. 1997, pp. 41-47, 2007

[12] R. S. McCourt, "Oregon's transportation planning rule goes into the shop for repairs", Transportation Research Record, no. 1981, pp. 56-59, 2006

[13] B. H. Mao, J. F. Guo, J. C. Chen, J. C.; S. P. Jia, "Some historical comments on urban transportation development of Beijing", Journal of Transportation networks Engineering and Information Technology, vol. 8, no. 3, pp. 6-13, 2008

[14] H. Ma, T. Hadden Loh, X. M. Yang, Z. Z. Sun, Q. X. Shi, "Evolution and effect of transportation policy on public transit: Lessons from Beijing", Transportation Research Record, no. 1994, pp. 94-100, 2007

[15] Q. I. Ahmed, H. P. Lu, S. Ye, "Urban transportation and equity: a case study of Beijing and Karachi", Transportation Research Part A: Policy and Practice, vol. 42, no. 1, pp. 125-139, 2008

[16] V. B. G. Campos, R. A. R. Ramos, D. M. S. Correia, "Multi-criteria analysis procedure for sustainable mobility evaluation in urban areas", Journal of Advanced Transportation, vol. 43, no. 4, pp. 371-390, 2009

[17] H. Castillo, D. E. Pitfield, "ELASTIC - A methodological framework for identifying and selecting sustainable transport indicators", Transportation Research Part D: Transport and Environment, vol. 15, no. 4, pp.179-188, 2010

[18] Y. J. Xu, Q. L. Da, "Standard and mean deviation methods for linguistic group decision making and their applications", Expert Systems with Applications, vol. 37, no. 8, pp. 5905-5912, 2010

[19] Y. L. Pei, Y. G. Wang, G. Yang, "Novel AHP algorithm to evaluate adaptability of transport system to urban sustainable development", Journal of Jilin University (Engineering and Technology Edition), vol. 38, no. 1 , pp. $42-47,2008$ 
[20] E. H. Forman, S. I. Gass, "The analytic hierarchy process - an exposition", Operations Research, vol. 49, no. 4, pp. 469-486, 2001

[21] C. M. Tsou, D. Y. Huang, "On some methods for performance ranking and correspondence analysis in the DEA context", European Journal of Operational Research, vol. 203, no. 3, pp. 771-783, 2010

[22] S. T. Gass, T. Rapcsak, "Singular value decomposition in AHP", European Journal of Operational Research, vol. 154, no. 3, pp. 573-584, 2004

[23] Y. B. Kim, Y. S. Kim, "An autonomous assessment system based on combined latent semantic kernels", Expert Systems with Applications, vol. 37, no. 4, pp. 3219-3228, 2010

[24] R. R. Boullosa, C. Alvarado Z, "On the sound environment of the city of Puerto Vallarta, Jalisco, Mexico", Journal of Applied Research and Technology, vol. 9, no. 3, pp. 430-442, 2011 